\title{
Effect of strain rate on bake hardening response of $\mathrm{BH} 220$ steel
}

\author{
Anindya Das ${ }^{1, a}$, Soumitro Tarafder ${ }^{1}$, S. Sivaprasad ${ }^{1}$, and Debalay Chakrabarti ${ }^{2}$ \\ ${ }^{1}$ MST Division, CSIR-National Metallurgical Laboratory, Jamshedpur, India \\ ${ }^{2}$ Metallurgical and Materials Engineering Department, IIT Kharagpur, Kharagpur, India
}

\begin{abstract}
This study aims at understanding the bake hardening ability of ultra low carbon BH220 steel at different strain rates. The as-received material has been pre-strained to four different levels and then deformed in tension under (a) as pre-strained state and (b) after baking at $170{ }^{\circ} \mathrm{C}$ for 20 minutes, at three different strain rates of $0.001,0.1$ and $100 / \mathrm{s}$. In both the conditions, yield stress increased with pre-strain and strain rate, but bake hardening ability was found to decrease when strain rate was increased. The strain rate sensitivity of the material was also found to decrease with bake hardening. Generation of dislocation forests and their subsequent immobility during baking treatment enables them to act as long range obstacles during further deformation. At higher strain rates, less amount of dislocations are produced which can interact with themselves and produce hardening, because of which bake hardening ability and the strain rate drops. A dislocation based strengthening model, as proposed by Larour et al. 2011 [7], was used to predict the yield stress values obtained at different conditions. The equation produced excellent co-relation with the experimental data.
\end{abstract}

\section{Introduction}

Bake hardenable steels are popular grades in automobile industries due to their high strength to weight ratio and excellent formability. Generally, these steels are used in the outer body panels of the automobiles. The fabrication involves a cold forming process to get the required shape followed by an industrial paint baking cycle $\left(170^{\circ} \mathrm{C}\right.$ for 20 minutes). The later process imparts an improved dent resistance of the component [1]. Cold deformation is essentially a pre-straining process during which fresh dislocations are produced. During baking process these dislocations are pinned down by the interstitial atoms by forming Cottrell atmosphere, thus providing an enhancement in strength during subsequent deformation through strain ageing phenomena [2].

This process of bake hardening is greatly influenced by the concentration of solute atoms, pre-strain levels, time and temperature of ageing, grain size of the material etc. The solute concentration helps in forming the Cottrell atmosphere over the generated dislocation cores, and the bake hardening ability increases if the solute concentration is increased up to a critical level where the Cottrell atmosphere tends to saturate [3]. Beyond the saturation limit, bake hardenability drops. Similar trend is also observed in case of pre-strain level, time and temperature of the ageing process $[1,4,5]$. On further increasing the solute concentration or ageing time and temperature, carbides starts precipitating which again increase the bake hardenability [4].

The bake hardening ability of these ultra low carbon steels is often quantified at quasi-static rates. But the nature of deformation is subjected to change when these components experience dynamic rate of loading, like in events of crash. This particular aspect has not been

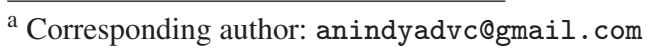

studied well and the available literature is scanty. This investigation aims at understanding the effects of strain rate on pre-strained as well as bake hardened ultra low carbon $\mathrm{BH} 220$ steel. The selected material, $\mathrm{BH} 220$ was obtained as sheets of $0.6 \mathrm{~mm}$ thickness and possesses 0.0027 wt.\% carbon in the matrix. The steel showed a ferritic structure (Fig. 1), with an average grain size of $33.75+2.3 \mu \mathrm{m}$.

\section{Experimental design}

Tensile specimens of $30 \mathrm{~mm}$ gauge length (ASTM E8M) were prepared from the as-received material along the rolling direction, to obtain the basic tensile properties as well as to decide the pre-strain levels. Tensile tests were performed at nominal strain rate of $0.001 / \mathrm{s}$. Pre-strain levels of 2, 4, 6 and $8 \%$ were selected for the current study, since these levels fall within the hardening region of the plastic deformation portion, as shown in Fig. 2.

After pre-straining, one set of specimens (designated: PS) were directly pulled in tension at three different strain rates $(0.001,0.1$ and 100/s).

The second pre-strained set of samples were aged at $170{ }^{\circ} \mathrm{C}$ for 20 minutes (designated: $\mathrm{PS}+\mathrm{BAK}$ ), and then pulled in tension at the same strain rates $(0.001,0.1$ and $100 / \mathrm{s})$. Tensile tests at 0.001 and $0.1 / \mathrm{s}$ strain rates were performed in a quasi-static servo-hydraulic test system, whereas the tests at 100/s were performed in a special high speed servo-hydraulic test system. The specimen design for all the tests are shown in Fig. 3.

\section{Results and discussions}

\subsection{Tensile and bake hardening properties}

The engineering stress-strain curves corresponding to PS and $\mathrm{PS}+\mathrm{BAK}$ conditions, at three different strain rates 


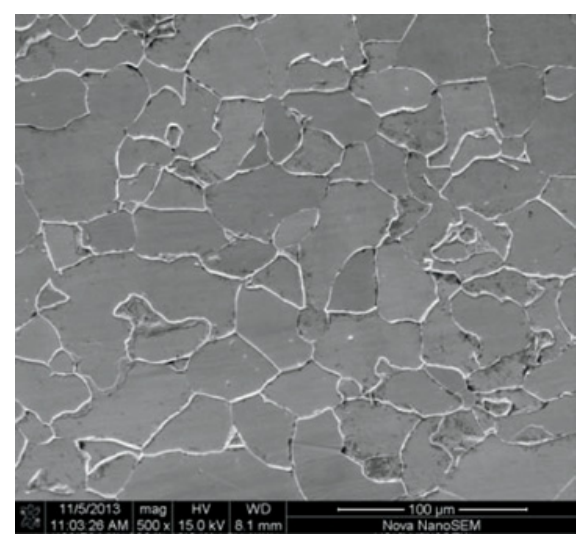

Figure 1. Microstructure of BH220 steel.

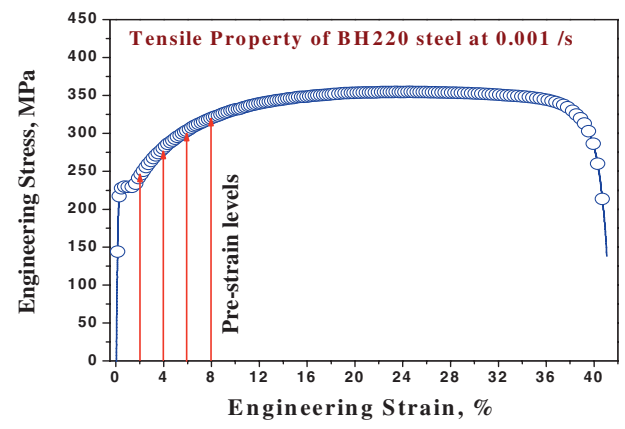

Figure 2. Tensile property of $\mathrm{BH} 220$ steel and the strain range selected for pre-straining deformation.

(a)

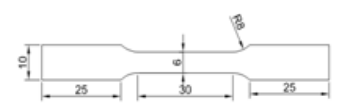

(b)

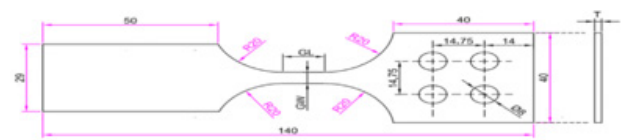

Figure 3. Specimen dimensions used for tensile deformation at (a) 0.001 and $0.1 / \mathrm{s}$ strain rate, and (b) 100/s All dimensions are in $\mathrm{mm}$.

are shown in Fig. 4. The tensile curves for PS do not show any yield point effect unlike that of PS+BAK. This is because, in as pre-strained condition, the generated dislocations remain free and experience no obstacle as in the case after bake hardening. The solute atoms lock the dislocations during bake hardening of the material after pre-straining, which needs a critical stress to get unlocked while deforming. This process of unlocking produces the enhanced yield point phenomenon. This critical stress required to unlock the pinned dislocations in bake hardened condition is much larger than the stress required to move the mobile dislocations in as pre-strained material. Thus the yield stress for bake hardened condition is higher than that of as pre-strained material. In Fig. 5, the variation of yield stress is shown with pre-strain and strain rate for both PS and PS + BAK conditions. Yield stress increases with both pre-strain level and strain rate.

To understand the bake hardening ability of the material, the difference in yield stress has been calculated for bake hardened condition with as-received as well as
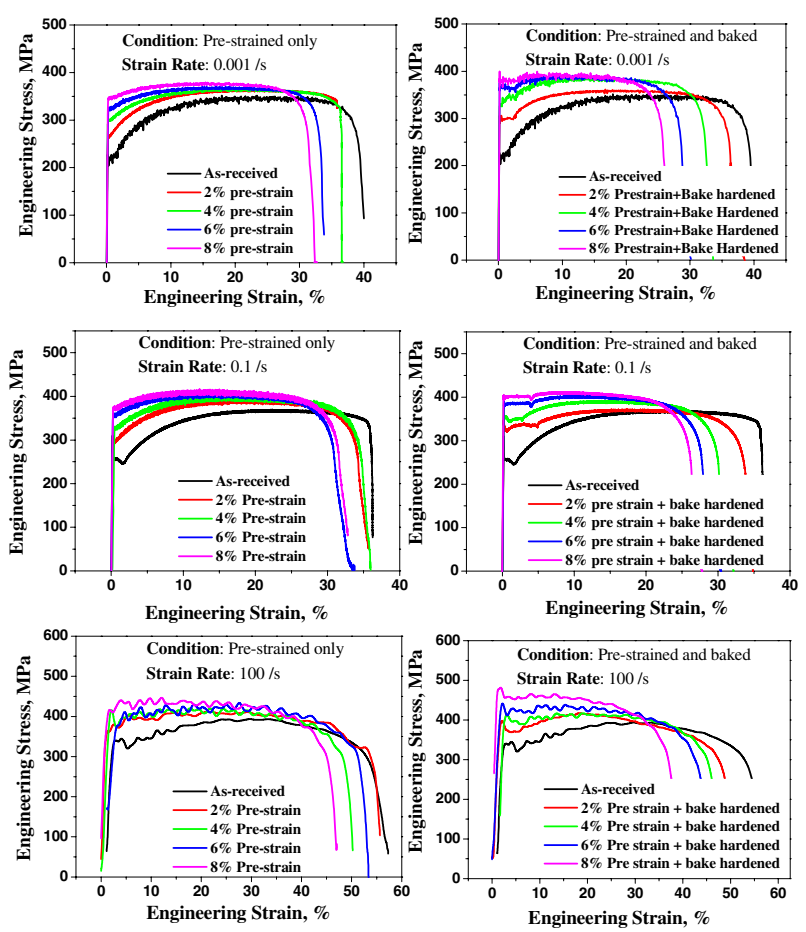

Figure 4. Engineering stress-strain curves obtained after prestraining and pre-strain with baking at 3 different strain rates.
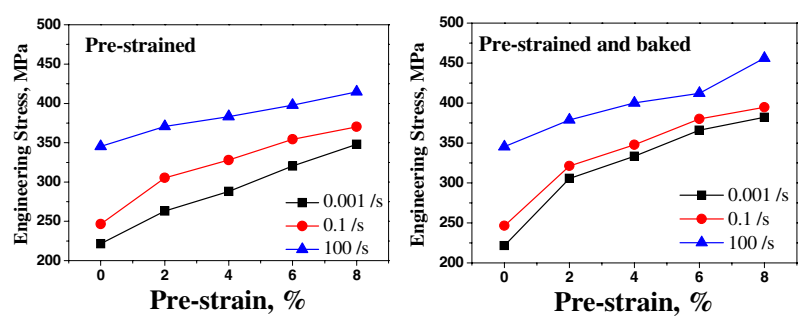

Figure 5. Yield stress values obtained after tensile deforming BH220 in as-received, PS and PS+BAK condition.

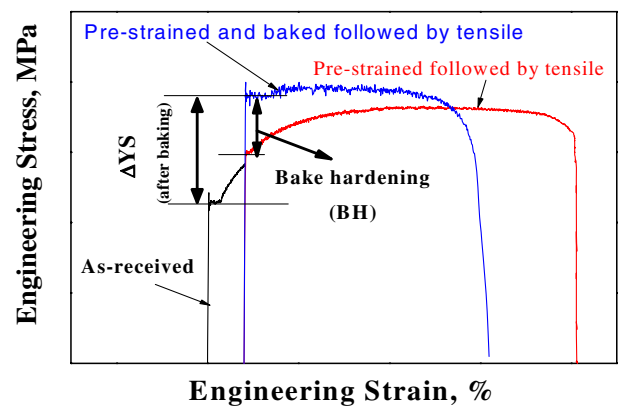

Figure 6. Schematic of different parameters.

with pre-strained material (as shown in Fig. 6), at each prestrain level and strain rate.

The difference in yield stress between bake hardened and as-received state is designated as $\triangle \mathrm{YS}$ and $\mathrm{BH}$ for the difference between bake hardened with its only prestrained condition.

Figure 7 shows the variation of $\Delta Y S$ with pre-strain and strain rate. The $\Delta Y S$ values increase as the prestrain range is increased at any particular strain rate but its value decreases as the strain rate increases at any 


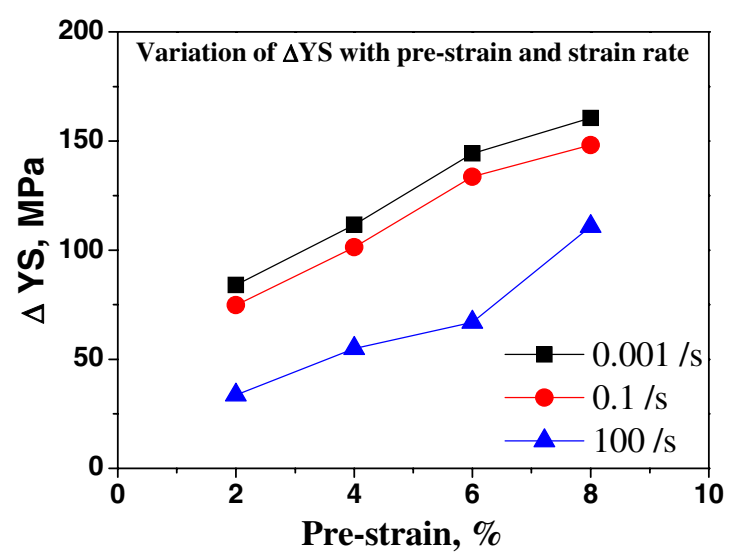

Figure 7. Variation of $\triangle Y S$ with pre-strain and strain rate.

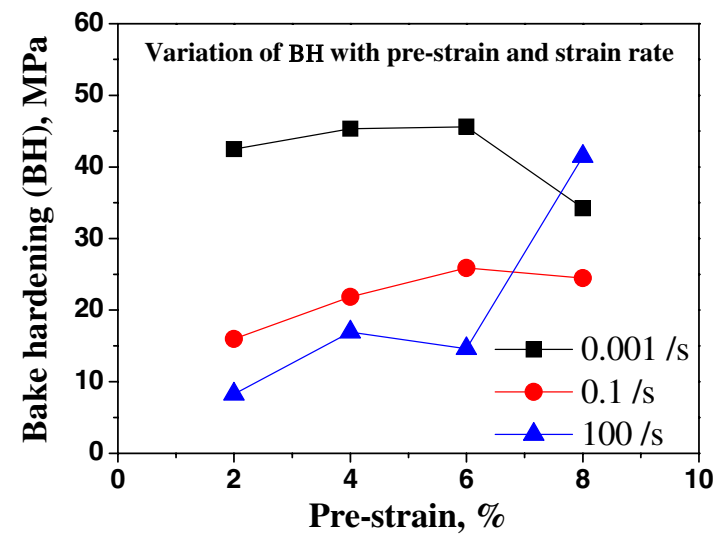

Figure 8. Variation of $\mathrm{BH}$ with pre strain and strain rate.

particular pre-strain level. The variation of $\mathrm{BH}$ with prestrain (Fig. 8) is also similar to that of $\triangle$ YS except that the $\mathrm{BH}$ values tend to drop for pre-strain $>6 \%$ for the quasi-static strain rates, but increase sharply after $6 \%$ pre-strain for high strain rate deformation. Pre-straining beyond $6 \%$, tends to reduce the dislocation density since the dislocation annihilation mechanisms may start beyond that point. Due to the reduced dislocation density, fewer dislocations are getting locked at highest pre-strain levels. In other words, more free solute atoms remain in the matrix when bake hardening is done at the $8 \%$ pre-strain level. As strain rate increases, the fresh dislocations produced during deformation also gets locked by the free solute atoms, and the bake hardening ability or $\mathrm{BH}$ increases. But overall, the $\mathrm{BH}$ value decreases as the strain rate is increased. This is because, with pre-straining, dislocation forests are produced which will increase with the pre-strain magnitude. After bake hardening, the subsequent locking of the dislocations in the forest by solute atoms will restrict the mobility of these dislocation forests produced and ultimately these will act as long range barriers during further deformation. As strain rate increases during further deformation, less amount of fresh dislocations are produced due to less amount of available time for deformation, which can interact with themselves and can produce the hardening.

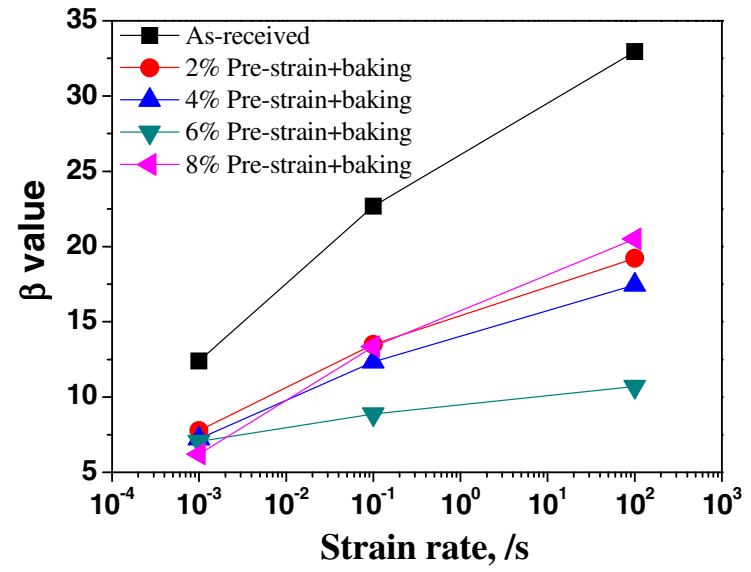

Figure 9. Variation of strain rate sensitivity with strain rate for as-received and bake hardened condition.

\subsection{Strain rate sensitivity after bake hardening}

Along with $\mathrm{BH}$ value, bake hardening also reduces the strain rate sensitivity of the material, as shown in Fig. 9. Semi-logarithmic strain rate sensitivity $(\beta)$ was calculated on yield stress at all strain rates for as-received and $\mathrm{PS}+\mathrm{BAK}$ condition using the following equation:

$$
\beta=\frac{\partial \sigma}{\partial(\log \dot{\varepsilon})}
$$

where, $\sigma$ is the yield stress value and $\dot{\varepsilon}$ is the strain rate.

The strain rate sensitivity increases with strain rate at all conditions but, the magnitude of this increase is more for the as-received condition compared to the bake hardened condition. In case of as-received material, the strength of the material is purely derived due to dislocation generation and its interaction with the interstitials during deformation. When the strain rate is increased, dislocation density increases and more dislocations interact with solute atoms which in turn increase the strength. The higher strain rate sensitivity for as-received material suggests that there is an increase in the contribution of thermally activated dislocation processes to the overall stress required for dislocation movement [6] and thus at high strain rates the properties are dominated by the stress for individual dislocation movement. In case of bake hardening, the solute atoms are tied to the dislocations generated during pre-straining prior to the post baking deformation. The newly formed dislocations during the post baked deformation will have less chance of interacting with the solute atoms and would be available as free mobile dislocations. Thus even if the strain rate is increased, the hardening due to dislocation-solute or dislocationdislocation interaction reduces leading to a lower strain rate sensitivity.

\subsection{Experimental vs. mathematical form of yield stress during bake hardening}

In general the flow stress during deformation can be decomposed into a thermally activated stress $\sigma^{*}$ due to short range obstacles and an athermal stress component $\sigma_{i}$ 
Table 1. Model parameters obtained for different conditions.

\begin{tabular}{|c|c|c|c|c|c|c|c|c|c|}
\hline & \multirow{2}{*}{ As-received } & \multicolumn{4}{|c|}{ Only pre-strain } & \multicolumn{4}{|c|}{ Bake hardened } \\
\hline Pre-strain & & $2 \%$ & $4 \%$ & $6 \%$ & $8 \%$ & $2 \%$ & $4 \%$ & $6 \%$ & $8 \%$ \\
\hline$\sigma_{i}(\mathrm{MPa})$ & 213.8 & 303.78 & 328.95 & 366.58 & 378.42 & 269.584 & 295.084 & 323.32 & 347.12 \\
\hline$\sigma_{0}^{*}(\mathrm{MPa})$ & 612.86 & 336.52 & 321.55 & 336.33 & 336.45 & 463.54 & 406.74 & 273.54 & 244.73 \\
\hline$\dot{\varepsilon}_{0}\left(\mathrm{~s}^{-1}\right)$ & $1.005 \mathrm{E} 8$ & $1.005 \mathrm{E} 8$ & $1.005 \mathrm{E} 8$ & $1.005 \mathrm{E} 8$ & $1.005 \mathrm{E} 8$ & $1.005 \mathrm{E} 8$ & $1.005 \mathrm{E} 8$ & $1.005 \mathrm{E} 8$ & $1.005 \mathrm{E} 8$ \\
\hline$\Delta G_{0}$ & $1.21 \mathrm{E}-19$ & $1.21 \mathrm{E}-19$ & $1.21 \mathrm{E}-19$ & $1.21 \mathrm{E}-19$ & $1.21 \mathrm{E}-19$ & $1.21 \mathrm{E}-19$ & $1.21 \mathrm{E}-19$ & $1.21 \mathrm{E}-19$ & $1.21 \mathrm{E}-19$ \\
\hline m' & 2.21597 & 2.21597 & 2.21597 & 2.21597 & 2.21597 & 2.21597 & 2.21597 & 2.21597 & 2.21597 \\
\hline
\end{tabular}

due to long range obstacles [7] as given below.

$$
\sigma=\sigma_{i}+\sigma^{*}=\sigma_{i, 0} \cdot \frac{G(T)}{G(0 K)}+\sigma^{*}(T, \dot{\varepsilon})
$$

where $\mathrm{G}(\mathrm{T})$ : temperature dependent shear modulus, $\mathrm{T}$ : temperature, $\dot{\varepsilon}$ : strain rate, $\sigma_{i, 0}$ : athermal stress component at zero thermal activation. Since, all the investigations have been made at room temperature $\left(28^{\circ} \mathrm{C}\right)$, the temperature dependency of the athermal flow stress component $\sigma_{i}$ has been neglected in Eq. (2). The Eq. (2) reduces to,

$$
\sigma=\sigma_{i, 0}+\sigma^{*}(T, \dot{\varepsilon}) \text {. }
$$

According to Larour, [7],

$$
\sigma^{*}(T, \dot{\varepsilon})=\sigma_{0}^{*} \cdot\left[1-\frac{k \cdot T \cdot \ln \left(\frac{\dot{\varepsilon}_{0}}{\dot{\varepsilon}}\right)}{\Delta G_{0}}\right]^{m^{\prime}}
$$

where, $\sigma_{0}^{*}$ : effective stress at zero thermal activation, $\dot{\varepsilon}$ : critical strain rate or pre-exponential factor, $\Delta G_{0}$ : free energy required to overcome the obstacle without the help of thermal activation $(\Delta G=0), m^{\prime}$ is strain rate exponent. Substituting Eq. (4) in Eq. (3), the expression for yield strength can be written as:

$$
\sigma_{Y S}=\sigma_{i}+\sigma_{0}^{*} \cdot\left[1-\frac{k \cdot T \cdot \ln \left(\frac{\dot{\varepsilon}_{0}}{\dot{\varepsilon}}\right)}{\Delta G_{0}}\right]^{m^{\prime}} .
$$

The equation has been used to model the YS variation observed in this investigation. Initial values of model parameters have been taken from the literature [8], and the parameters have been tuned for the convergence. The critical strain rate $\left(\dot{\varepsilon}_{0}\right), \Delta G_{0}$ and strain rate exponent (m') have been kept constant in all the cases, since these thermal activation parameters are specific to the material, independent of their condition [9]. The fitting procedure produced a goodness of fit of more than $90 \%$ in all the cases. The experimentally obtained and modelled yield stress of PS and PS +BAK condition are shown in Figs. 10 and 11 respectively. The experimental and modelled yield strength values match reasonably well in all the conditions. Table 1 lists the model parameters obtained at different conditions. For as-received material the athermal flow stress component $\sigma_{i}$ is very high for PS when compared to $\mathrm{PS}+\mathrm{BAK}$ condition. But it increases with increase in

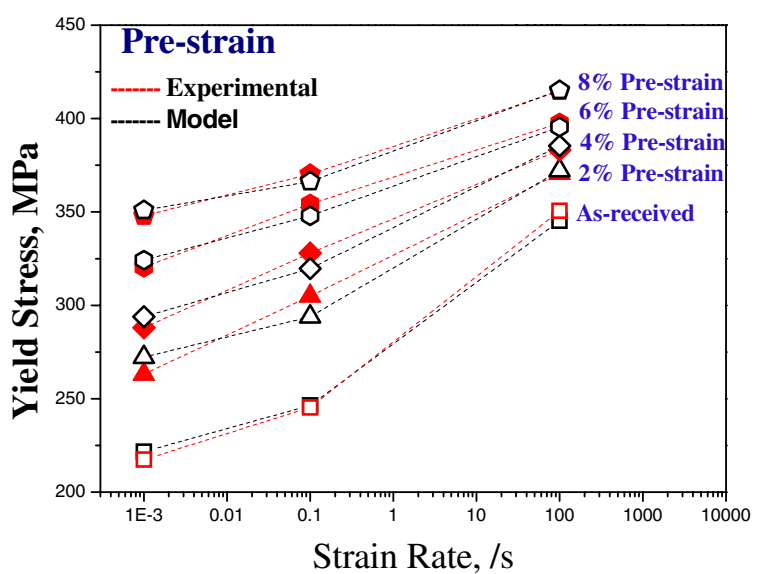

Figure 10. Experimental and predicted yield stress values of only pre-strained material at various strain rate.

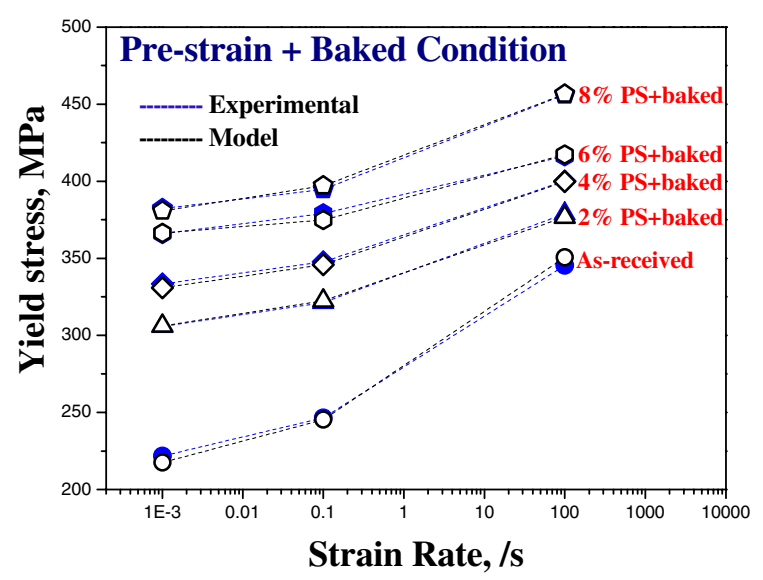

Figure 11. Experimental and predicted yield stress values of bake hardened condition at various pre-strain and strain rate.

pre-strain in both only pre-strained and pre-strain with bake hardened conditions. This stress due to long range obstacle can be attributed to the dislocation forest which is generating during pre-straining process, which also increase as the pre-strain range is increased.

\section{Conclusion}

Dislocation forest generated during pre-straining acts as long range obstacle after it has been arrested by solute atoms while bake hardening. These long range obstacles reduce the strain rate sensitivity, as well as bring down the bake hardening ability of the material. 


\section{References}

[1] S. Berbenni, V. Favier, X. Lemoine, M. Berveiller, Scripta Materialia, 51 (2004)

[2] A. H. Cottrell, B. A. Bilby; Proc. of Phys Society A, 62 (1949)

[3] S. Hanai, N. Takemoto, Y. Tokunaga and Y. Mizuyama; Trans ISIJ, 24 (1984)

[4] P. Elsen and H. P. Hougardy; Steel Research (64) (1993)
[5] A. K. De, S. Vandeputte and B. C. De Cooman; Scripta Materialia, 41 (1999)

[6] R.S. Kircher, A. K. De, D. K. Matlock, J. G. Speer, MS\&T conference proceedings (2004)

[7] P. Larour, K. Dahmen, W. Bleck, Steel research Int. 82 (2011)

[8] P. Larour, Ph.D. thesis, RWTH Aachen (2010) 